\title{
Classical and novel organohalogen compounds (PCBs and PBDEs) in hake (M. merluccius, L.) from the Mediterranean and Atlantic coasts (France)
}

\author{
X. Bodiguel, J. Tronczyński, V. Loizeau, C. Munschy, N. Guiot, \\ A. M. Le Guellec, N. Olivier, F. Roupsard \& C. Mellon \\ Ifremer, Departments BE and HMT, France
}

\begin{abstract}
Levels of polychlorinated biphenyls (PCBs) and polybrominated diphenyl ethers (PBDEs) were determined in the muscle and liver of European hakes (Merluccius merluccius, L.) from the Mediterranean and Atlantic coasts (France). The liver was always the most contaminated organ by both groups of compounds. Hakes from the Gulf of Lions (Mediterranean) present concentrations of PCBs and PBDEs 1.6 to 13.5 times higher than hakes of a similar size from the Bay of Biscay (Atlantic). Although PCBs present higher levels compared to PBDEs, their concentrations were significantly correlated. The contaminant patterns in hakes were similar in the two studied areas, and were dominated by higher chlorinated PCBs (CB153, 138, 180 and 170), and lower brominated PBDEs congeners (BDE47, 100, 49, and 99). Concentrations globally increase with hake size, and males appear to be more contaminated than females of the equivalent size. However, the compound levels also depend on the physiological status of fish.

Keywords: Merluccius merluccius, demersal fish, polychlorinated biphenyls, polybrominated diphenyl ethers, Gulf of Lions, Bay of Biscay.
\end{abstract}

\section{Introduction}

During recent decades, persistent halogenated compounds (PHCs) have been largely used and emitted to the environment. Two compound groups regularly found in marine biota are polychlorinated biphenyls (PCBs) and polybrominated 
diphenyl ethers (PBDEs). PCBs were used in a variety of products such as cooling and isolation fluids until they were banned in France in 1987. PBDEs are a class of additive flame retardants that are currently used in electronics, automobiles, textiles, and in building materials (de Wit [1]). Besides old deposits in sediments, PHCs continuing environmental emissions still occur, and may act as novel sources in exposure of marine organisms. Due to their high persistence, hydrophobicity and lipid propensity, they are accumulated in fat tissues of organisms and biomagnified along trophic webs (Boon et al. [2]; Burreau et al. $[3,4]$ ). Both compound groups may have adverse effects on fish (Holm et al. [5]). The European hake (Merluccius merluccius, L.) is widely distributed along the Mediterranean and NE Atlantic coasts, and represents an important commercial interest (Alheit and Pitcher [6]). With a high trophic level (Ferraton et al. [7]), this demersal fish is potentially exposed to the accumulation of PHCs. The main aims of this study were to determine the levels and chemical profiles of PBDEs and PCBs in different organs of hake (liver and muscle), and to compare this contamination between the Mediterranean and Atlantic coasts of France.

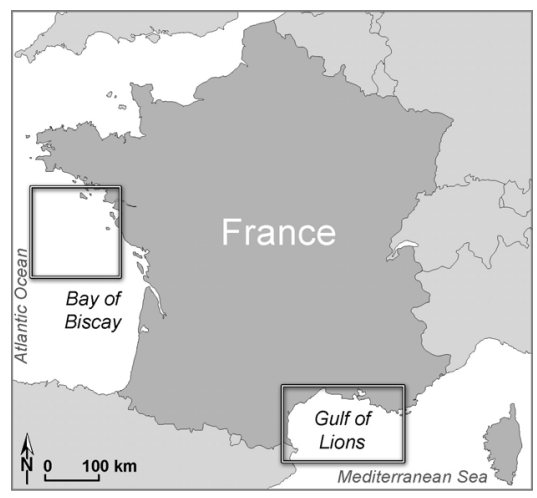

Figure 1: $\quad$ Map of the study areas.

\section{Material and methods}

\subsection{Sampling}

The study areas are the Gulf of Lions, and the northern part of the Bay of Biscay, two regions of the French coasts (fig. 1). The Gulf of Lions, situated in the NW Mediterranean, is one of the most important continental shelves in the Mediterranean (Roussiez et al. [8]). It receives high freshwater discharges from the Rhône River watershed, which drains heavily industrialized regions of southern France. The Bay of Biscay, situated in the NE Atlantic, receives freshwater discharges from the Loire River, in western France. Hakes were caught during bottom-trawl cruises, on the continental shelves (between 50 and 120 meters depth), in spring 2001, spring 2002 and autumn 2002 in the Bay of 
Biscay, and in spring 2004, spring and autumn 2005 and autumn 2006 in the Gulf of Lions.

A total of 94 hakes with total length (TL) from 10 to $70 \mathrm{~cm}$ were sampled for organic contaminant analysis. 52 were analysed for both contaminant families, and 42 were only analysed for PCBs. Fish were primarily pre-treated in the laboratory for total body weight, TL, macroscopic sex determination and dissection of tissues to cut off organs (muscle and liver). Only specimens $\geq 25 \mathrm{~cm}$ TL were sexually differentiated. Muscles and livers were weighted and stored in pre-cleaned glass jars at $-20^{\circ} \mathrm{C}$. All sampled tissues were freeze dried, and ground to obtain a fine homogeneous powder. Their water content was estimated from the weight lost after freeze drying.

\subsection{Chemical analysis}

\subsubsection{Sample treatment and analysis}

The method used was already described for both PBDEs and PCBs analysis (Johansson et al. [9], Bodin et al. [10]). Briefly, between 100mg and 5g dry weight (d.w.) of biological tissues were extracted with dichloromethane using a pressurised solvent extraction (ASE, Dionex Corp., CA) for the analysis of PBDEs and PCBs, or with hexane/acetone mixture (80:20) using SOXTEC, for only PCB analysis. The samples were spiked with recovery standards (BDE139, CB30, CB198 and CB209). The removal of co-extracted lipids was performed by gel permeation chromatography (GPC) on a laboratory prepared column (Bio Beads SX-3 200-400 Mesh, 460mm x 26mm column). The extracts were further purified and fractionated on a two layer silica/alumina column $\left(\mathrm{H}_{2} \mathrm{O} \quad 5 \%\right.$ deactivated silica gel and alumina) using hexane and hexane/dichloromethane $(9: 1)$ as an eluent. The extracts were finally treated with sulphuric acid to further remove remaining lipids.

Polybrominated diphenyl ethers were analysed by GC/MS in electron capture negative ionisation mode (ECNI) using methane as the reagent gas. The column was a DB-1, $15 \mathrm{~m} \times 248 \mu \mathrm{m}$ i.d. $\times 0.10 \mu \mathrm{m}$ film thickness (J\&W Scientific), fitted with a $1-2 \mathrm{~m}$ deactivated non-polar retention gap column. The ionisation voltage was about $170 \mathrm{eV}$, set to the optimum by tuning. Spectra were recorded using selected ion monitoring at $\mathrm{m} / \mathrm{z} 79,81$ and 161 for all PBDEs except BDE209 for which the 486 and 488 ions were recorded. The quantification were carried out using eight-level calibration curves in the 2-200pg range except for BDE209 which was calculated using a calibration curve in the 10-200pg range. Polychlorinated biphenyls CBs were analysed by high resolution gas chromatography fitted with two electron capture detectors (ECD), using two columns of different polarities: a DB-5 (5\% phenyl-methylpolysiloxane) column of $60 \mathrm{~m} \times 0.25 \mathrm{~mm}$ (film thickness $0.25 \mu \mathrm{m})$, and a HT8 (8\% phenyl-polysiloxanecarborane) column of $50 \mathrm{~m} \times 0.25 \mathrm{~mm}$ (film thickness $0.25 \mu \mathrm{m}$ ). Hydrogen was the carrier gas at a linear velocity of $27.6 \mathrm{~cm} . \mathrm{s}^{-1}$. Concentrations were calculated by external multi level calibration regression in the linear range of the response of the detector. Whenever necessary two calibration curves were used to offset the non linear response of the ECD detector, i.e., the first in the range of 2-75pg and the second of 75-250pg of injected individual congeners. The standards 
added before the extraction were used as recovery surrogates, but concentrations were not corrected for recovery (Munschy et al. [11]).

\subsubsection{Validation of analytical method}

The overall internal QA/QC procedures included laboratory and field blanks, analyses of replicate samples for precision determination and the use of internal recovery standards added to each sample prior to extraction. Mean percent recoveries for the internal standards were $61 \pm 10 \%, 86 \pm 11 \%, 97 \pm 10 \%$ for PCB congeners 30, 198, and 209, respectively and $94 \pm 20 \%$ for BDE- 139 . Analyses of Reference Materials (CRM 349, SRM 2977 NIST and WMF-01 Wellington laboratories) were routinely incorporated into the analysis of different batches of samples. The laboratory proficiency for CBs and PBDEs analysis is also evaluated through participation in the QUASIMEME (Quality Assurance of Information for Marine Environmental Monitoring in Europe) intercomparison exercises. The satisfactory z-scores are generally obtained for the CBs in biota samples (ex. 2006/2007 Quasimeme exercises z-scores ranged from -0.7 to 0.7 and from -1.7 to 0.2 ).

\section{Results and discussion}

\subsection{Contamination levels}

The present study focused on the levels of PBDEs and PCBs in muscle and liver of hakes caught in the Bay of Biscay (BoB) and in the Gulf of Lions (GoL). The systematic prevalence of the BDE47 and CB153 in all analysed samples allows using these compounds to illustrate the contamination levels of PBDEs and PCBs. Liver was always the most contaminated organ, with concentrations of BDE47 ranging between 3.1 and 28ng. $\mathrm{g}^{-1} \mathrm{~d} . \mathrm{w}$. in the BoB and between 2.7 and 65 ng. g $^{-1}$ d.w. in the GoL. For CB153, liver concentrations ranged between 55 and 567ng. ${ }^{-1}$ d.w. in the BoB and between 59 and 2154ng.g ${ }^{-1}$ d.w. in the GoL. The liver concentrations were 5 to 69 times higher than muscle for BDE47, and 13 to 59 times higher than muscle for CB153. Muscle concentrations of BDE47 ranged between 0.09 and $0.57 \mathrm{ng} . \mathrm{g}^{-1} \mathrm{~d}$.w. in the $\mathrm{BoB}$ and between 0.42 and $6.1 \mathrm{ng} . \mathrm{g}^{-1} \mathrm{~d}$.w. in the GoL. For CB153, muscle concentrations ranged between 2.7 and 18ng. $\mathrm{g}^{-1}$ d.w. in the $\mathrm{BoB}$ and between 10 and 163ng.g $\mathrm{g}^{-1} \mathrm{~d}$.w. in the GoL. Compared to lipid-normalized concentrations of BDE47 reported by Boon et al. [2] in cods from the North Sea (livers from 63 to $307 \mathrm{ng}^{-g^{-1}}$ lipid and muscles from 26 to $74 \mathrm{ng}^{-g^{-1}}$ lipid), the concentrations in same hake tissues from the Bay of Biscay (6.8 to $42.5 \mathrm{ng} . \mathrm{g}^{-1}$ lipid in muscles and 7.4 to $25.2 \mathrm{ng} \cdot \mathrm{g}^{-1}$ lipid in livers) and the Gulf of Lions (3.7 to 91.6ng. $\mathrm{g}^{-1}$ lipid in muscles and 6 to $119.8 \mathrm{ng} . \mathrm{g}^{-1}$ lipid in livers) are lower. Boon et al. [2] also reported BDE47 concentrations in another fish species from the North Sea (for herring, livers from 19 to 52ng.g ${ }^{1}$ lipid and muscles from 37 to $38 \mathrm{ng}^{-g^{-1}}$ lipid, and for whiting, livers from 70 to

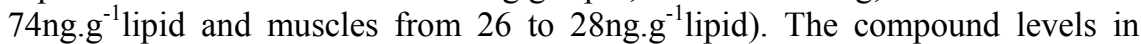
muscles and livers caught in the GoL were systematically higher than levels in the BoB (between 1.6 to 11 times for BDE47 and between 1.7 to 13.5 times for 
CB153), fig. 2. Kiviranta et al. [12] suggested for herring from the Atlantic and Baltic seas, differences in organohalogen concentrations may be caused by both, variation in exposure levels and in feeding habits of fish. However, the dietary intake is generally identified as the main pathway of fish contamination by the hydrophobic organic compounds. The higher levels of PHCs in Mediterranean hakes might be related to the Rhône River loads coming from urbanised and industrialised watershed in southern France. Furthermore, the riverine discharges are rather constrained into the Gulf of Lions, because of the low tidal dynamics, and thus resulting in possibly higher exposure levels in its marine habitats.

GoL
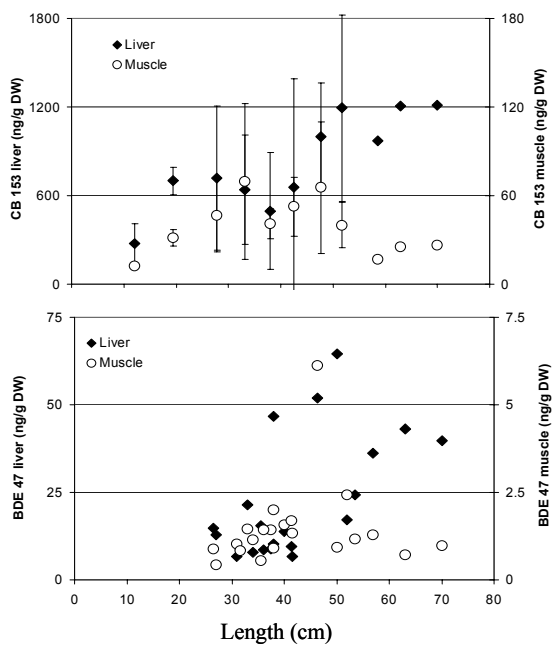

BoB
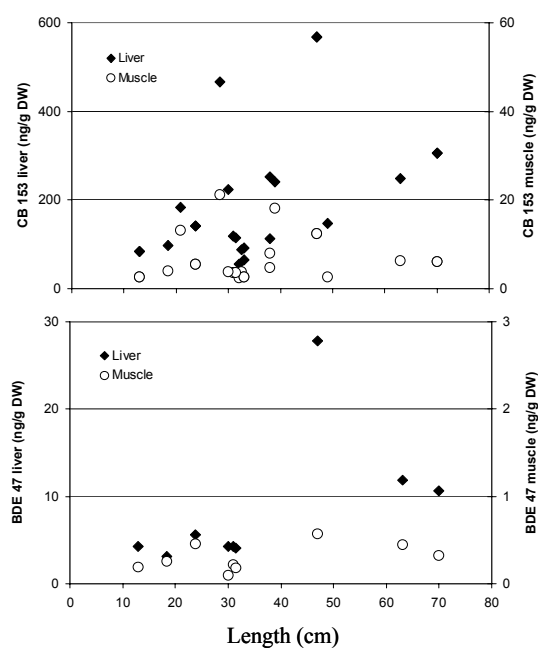

Figure 2: $\quad$ CB153 and BDE47 concentrations (ng. $\left.\mathrm{g}^{-1} \mathrm{~d} . \mathrm{w}.\right)$ in muscles and livers of hakes against hake lengths; fish samples from the Gulf of Lions (GoL) and the Bay of Biscay (BoB).

The concentrations of BDE47 and CB153 in hake muscles and livers versus the hake lengths show great variability, fig. 2. Despite this high variability, a tendency of compounds concentrations increase in liver with hake lengths may be distinguished. However, if all data are examined together, as presented in figure 2, this trend of contamination increase with fish length is not significant. Since fish length is directly related to fish age, the concentrations increase of CB153 and BDE47 with fish size is attributed to the bioaccumulation over time and storage of the compounds in lipids and their slow depuration rates by organisms. Previous studies showed also that PBDE and PCB levels increase with the age/size of fish (Parmanne et al. [13]; Loizeau et al. [14]). However, the high concentration variability in our set of fish samples suggests that length is not the only factor to act on the contamination levels. Indeed, a part of the variability may be due to a contamination difference between males and females. For instance, the levels of CB153 and BDE47 in livers of larger males $(47-53 \mathrm{~cm}$ TL) are higher than levels in female livers, fig. 3 . This variation can be due to a 
female decontamination during spawning (Loizeau et al. [14]). Moreover, this phenomenon can be magnified by the lower growth rate of males (Recasens et al. [15]; Piñeiro and Saínza [16]), so at equivalent size, they are older and have more bioaccumulated. This growth dimorphism between sexes suggests that age is probably a more important factor than body size in the PBDE and PCB accumulation in hakes.
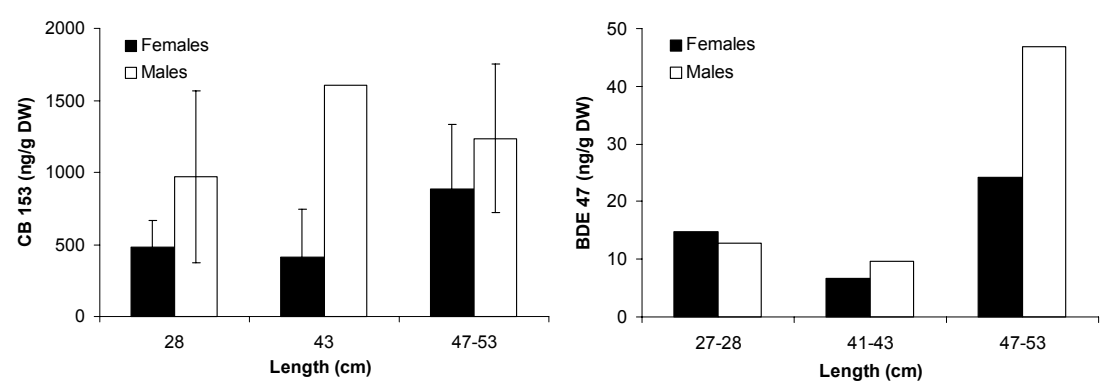

Figure 3: $\quad \mathrm{CB} 153$ and BDE47 concentrations in liver of females and males from the Gulf of Lions.

The observed interindividual variability of contaminant levels may be also related to disparity in fish environmental habits, possibly leading to high dissimilarity in dietary exposure levels. Finally, other factors, such as variations in physiological conditions (reproduction, diet status, overall fitness) of the individuals have been also identified as being able to influence PHCs contamination in fish (Loizeau et al. [14]; van der Oost et al. [17]).

\subsection{Contamination distribution}

\subsubsection{Contamination profiles}

The contaminant patterns in hakes were dominated by lower brominated congeners. Among congeners, the predominant compound was always BDE47, followed by BDEs 100, 49, 99 and 154. Similar patterns have been also reported in fish previously (Law et al. [18]). Bodin et al. [19] reported PBDE profiles in crustaceans from French coasts dominated by BDEs 100, 99 and 28. Even though PBDE profiles are efficiently transferred to fish via food (Isosaari et al. [20]), this pattern may be also influenced by debromination of some congeners in the intestinal tract of fish. According to dietary exposure studies on common carp (Cyprynus carpio L.), debromination converted BDE99 to BDE47 and BDE183 to BDE154 (Stapleton et al. [21]). However, in our study, no significant difference in PBDE patterns was observed in different organs of hakes from different regions ( $\mathrm{GoL}$ and $\mathrm{BoB})$, fig. 4.

Among PCB congeners, the higher chlorinated compounds were predominant. Patterns were dominated by hexachlorobiphenyls (CB153 and CB138), followed by heptachlorobiphenyls (CB180 and CB170). Due to their high octanol-water coefficients (Kow), they are efficiently accumulated by marine organisms, and 
are considered persistent, due to chlorine substitution positions (Kannan et al. [22]). The CB153 and CB138 were also prevailing in another fish species (herring and salmon) from the Baltic Sea and the northern Atlantic (Burreau et al. [4]). However heptachlorobiphenyls (CB180 and CB170) can be found in lower concentrations than CB 118, a pentachlorobiphenyl. As for PBDEs, no significant difference of PCB patterns was observed in hake's muscle and liver sampled in different regions, fig. 4.
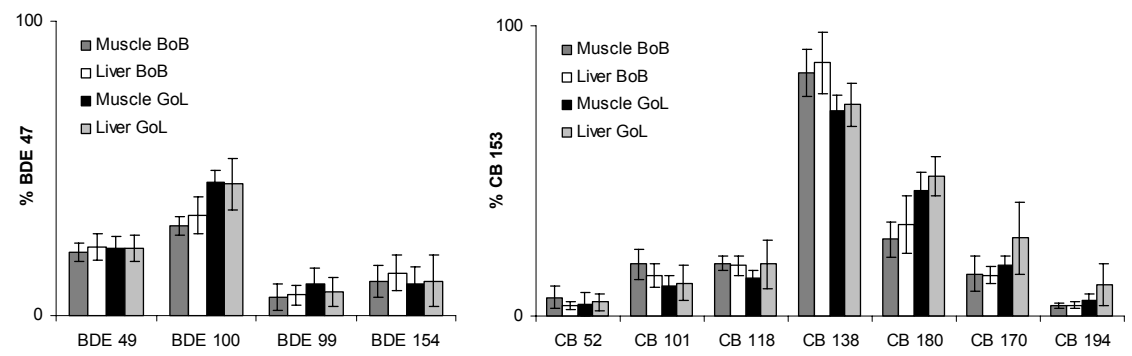

Figure 4: Concentrations of $\mathrm{PBDE}$ and $\mathrm{PCB}$ congeners normalised to the BDE47 and the CB153 in muscle and liver of hakes from the Bay of Biscay (BoB) and the Gulf of Lions (GoL).

Liver
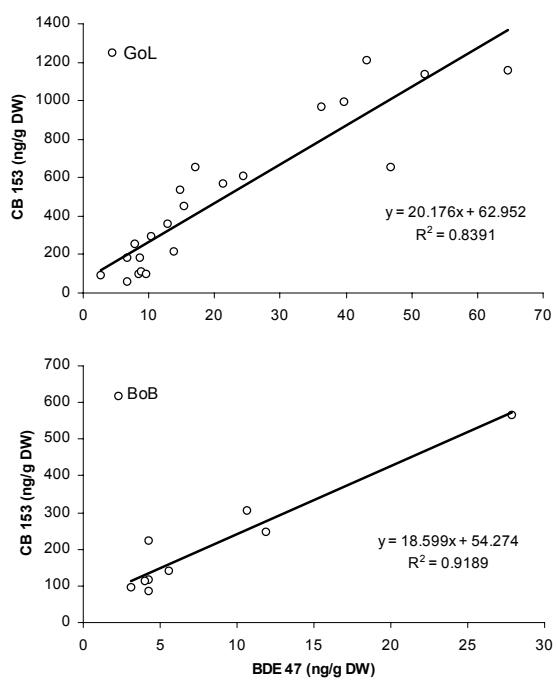

Muscle
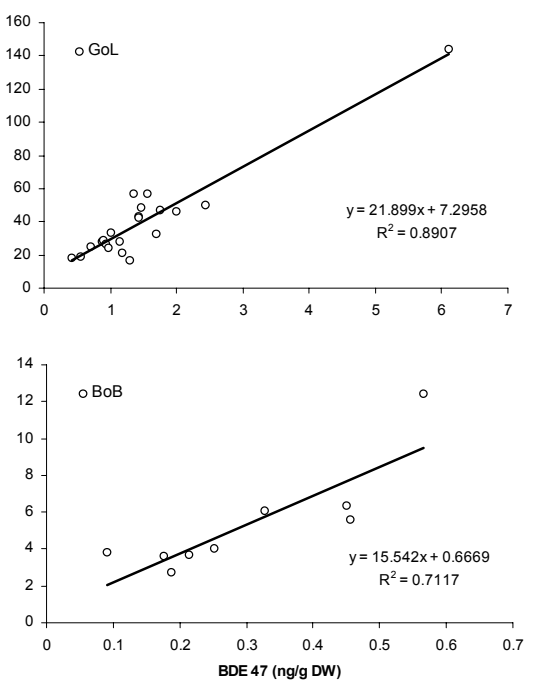

Figure 5: Comparison between $\mathrm{CB} 153$ and BDE47 concentrations (ng. $\mathrm{g}^{-1}$ d.w.) in liver and muscle of hakes from the Gulf of Lions (GoL) and the Bay of Biscay (BoB). 


\subsection{PCB/PBDE correlations}

Observed differences between PCB and PBDE concentration levels in hakes are in agreement with generally lower levels of PBDEs in the environment (Burreau et al. [4]; Johansson et al. [9]; Parmanne et al. [13]; Bodin et al. [19]). Even if the source emissions of PBDEs and PCBs are quite different, we attempted to correlate the $\mathrm{CB} 153$ and the BDE47 concentrations in our hake tissue samples. The CB153 concentrations in liver and muscle of hakes from the BoB and the GoL showed a strong correlation with the BDE47 concentrations, fig. 5. The significant BDE47/CB153 correlation tends to indicate similar bioaccumulation mechanisms in fish for both compounds.

\section{Acknowledgements}

This work was partially funded by the Regional Council of LanguedocRoussillon. Ifremer and Merlumed ANR- ECCO-ECODYN research programs also supported this project. We would like to thank all the crews of research vessels $\mathrm{O} / \mathrm{V}$ Europe and $\mathrm{O} / \mathrm{V}$ Thalassa (Ifremer), and $\mathrm{O} / \mathrm{V}$ Côte de la Manche (INSU). The authors are grateful to Pierre Bodenes for drawing the map, Luisa Metral and Franck Ferraton for their laboratory assistance.

\section{References}

[1] de Wit, C.A., An overview of brominated flame retardants in the environment, Chemosphere 46, pp. 583-624, 2002.

[2] Boon, J.P., Lewis, W.E., Tjoen-A-Choy, M.R., Allchin, C.R., Law, R.J., De Boer, J., Ten Hallers-Tjabbes, C.C. and Zegers, B.N., Levels of polybrominated diphenyl ether (PBDE) flame retardants in animals representing different trophic levels of the North Sea food web. Environmental Science and Technology, 36, pp. 4025-4032, 2002.

[3] Burreau, S., Zebuhr, Y., Broman, D., Isaac, R., Biomagnification of polychlorinated biphenyls (PCBs) and polybrominated diphenyl ethers (PBDEs) studied in pike (Esox lucius), perch (Perca fluviatilis) and roach (Rutilus rutilus) from the Baltic Sea. Chemosphere, 55, pp. 1043-1052, 2004.

[4] Burreau, S., Zebühr, Y., Broman, D., and Ishaq, R., Biomagnification of PBDEs and PCBs in food webs from the Baltic Sea and the northern Atlantic Ocean. Sci. of Total Env., 366, pp. 659-672, 2006.

[5] Holm, G., Norrgren, L., Andersson, T., Thuren, A., Effects of Exposure to Food Contaminated with PBDE, PCN or PCB on Reproduction, Liver Morphology and Cytochrome-P450 Activity in the 3-Spined Stickleback, Gasterosteus aculeatus. Aquat. Toxicol., 27, pp. 33-50, 1993.

[6] Alheit, J., and Pitcher, T. J., Hake: Fisheries, Ecology and markets, Chapman \& Hall, London, 478 p, 1995.

[7] Ferraton, F., Harmelin-Vivien, M., Mellon-Duval, C., Souplet, A., Spatiotemporal variation in diet may affect condition and abundance of juvenile 
European hake in the Gulf of Lions (NW Mediterranean). Mar. Ecol. Prog. Ser., 337, pp. 197-208, 2007.

[8] Roussiez, V., Aloisi, J. C., Monaco, A., Ludwig, W., Early muddy deposits along the Gulf of Lions shoreline: A key for a better understanding of landto-sea transfer of sediments and associated pollutant fluxes. Mar. Geol., 222-223, pp. 345-358, 2005.

[9] Johansson, I., Héas-Moisan, K., Guiot, N., Munschy, C., Tronczynski, J., Polybrominated diphenyl ethers (PBDEs) in mussels from selected French coastal sites: 1981-2003. Chemosphere, 64, pp. 296-305, 2006.

[10] Bodin, N., Abarnou, A., Le Guellec, A.M., Loizeau, V, Philippon, X., Organochlorinated contaminants in decapod crustaceans from the coasts of Brittany and Normandy (France). Chemosphere, 67, pp. 536-547, 2007.

[11] Munschy, C., Moisan, K., Tronczynski J., Levels and patterns of PCBs and PCDD/Fs in different tissues of the marine flatfish dab (Limanda Limanda) from the English Channel, France. Organohal. Compd., 66, pp. 1695-1703, 2004.

[12] Kiviranta, H., Vartiainen, T, Parmanne, R, Hallikainen, A., Ruokojarvi, P., Koistinen, J., PCDD/s and PCBs in Baltic herring during the 1990's. Organohalogen Compd., 57, pp. 153-156, 2003.

[13] Parmanne, R., Hallikainen, A., Isosaari, P., Kiviranta, H., Koistinen, J., Laine, O., Rantakokko, P., Vuorinen, P.J., Vartiainen, T., The dependence of organohalogen compound concentrations on herring age and size in the Bothnian Sea, northern Baltic. Mar. Poll. Bull., 52, pp. 149-161, 2006.

[14] Loizeau, V., Abarnou, A., Cugier, P., Jaouen-Madoulet, A., Le Guellec, A.M., Menesguen, A., A model o PCB Bioaccumulation in the Sea Bass Food Web from the Seine Estuary (Eastern English Channel). Mar. Poll. Bull., 43, pp. 242-255, 2001.

[15] Recasens, L., Lombarte, A., Morales-Nin, B., Torres, G.J., Spatiotemporal variation in the population structure of the European hake in the NW Mediterranean. J. Fish. Biol., 53, pp. 387-401, 1998.

[16] Piñeiro and Saínza, M., Age estimation, growth and maturity of the European hake (Merluccius merluccius Linnaeus, 1758) from Iberian Atlantic waters. ICES J. Mar. Sci., 60, pp. 1086-1102, 2003.

[17] van der Oost, R., Beyer, K., Vermeulen, N.P.E., Fish bioaccumulation and biomarkers in environmental risk assessment: a review. Environmental Toxicology and Pharmacology, 13, pp. 57-149, 2003.

[18] Law, R.J., Allchin, C.R., de Boer, J., Covaci, A., Hertzke, D., Lepom, P., Morris, S., Tronczynski, J., de Wit, A.C., Levels and trends of brominated flame retardants in the European environment. Chemosphere, 64, pp. $187-$ 208, 2006.

[19] Bodin, N., Abarnou, A., Fraisse, D., Defour, S., Loizeau, V., Le Guellec, A.M., Philippon, X., PCB, PCDD/F and PBDE levels and profiles in crustaceans from the coastal waters of Brittany and Normandy (France). Mar. Poll. Bull., 54, pp. 657-668, 2007.

[20] Isosaari, P., Hallikainen, A., Kiviranta, H., Vuorinen, P.J., Parmanne, R., Koistinen, J., Vartiainen, T., Polychlorinated dibenzo- $p$-dioxins, 
dibenzofurans, biphenyls, naphthalenes and polybrominated diphenyl ethers in the edible fish caught from the Baltic Sea and lakes in Finland. Environ. Pollut., 141, pp. 213-225, 2006.

[21] Stapleton, H.M., Letcher, R.J., Baker, J.E., Debromination of Polybrominated Diphenyl Ether Congeners BDE 99 and BDE 183 in the Intestinal Tract of the Common Carp (Cyprinus carpio) Environ. Sci. Technol., 38, pp. 1054-1061, 2004.

[22] Kannan, N., Reusch, T.B.H., Schultz-Bull, D.E., Petrick, G, Duinker, J.C., Clorobiphenyls : model compound for metabolism in food chain organisms and their potential use as ecotoxicological stress indicators by application of the metabolic slope concept. Environ. Sci. Technol., 29, pp. 1851-1859, 1995. 